\title{
Desenho e funcionamento dos mecanismos de controle e accountability das agências reguladoras brasileiras: semelhanças e diferenças*
}

\author{
Marcos Vinicius Pó** \\ Fernando Luiz Abrucio***
}

SuMÁRIO: 1. Introdução; 2. As reformas administrativas brasileiras; 3. A criação e implementação das agências reguladoras; 4. Definições de controle e accountability e possíveis mecanismos; 5 . Desenho institucional básico das agências reguladoras brasileiras; 6 . Seleção dos objetos de pesquisa; 7. Breve panorama dos setores estudados: energia elétrica, telecomunicações, saúde suplementar e transportes terrestres; 8. Resultados e observações; 9. Conclusões e observações finais.

SUMMARY: 1. Introduction; 2. The Brazilian administrative reforms; 3. Creation and implementation of the regulatory agencies; 4 . Definitions for control and accountability and possible mechanisms; 5. Basic institutional design of the Brazilian regulatory agencies; 6. Selecting the objects of research; 7. Outlook on the studied sectors: electricity, telecommunications, supplemental health care, and land transportation; 8. Results and observations; 9. Conclusions and final remarks.

PAlAVRAS-CHAVE: agências reguladoras; regulação; accountability; controle da burocracia.

KEY WORDS: regulatory agencies; regulation; accountability; bureaucracy control.

\footnotetext{
* Artigo recebido em fev. e aceito em maio 2006.

** Coordenador executivo do Instituto Brasileiro de Defesa do Consumidor (Idec). Doutorando e mestre em administração pública pela Eaesp/FGV. Endereço: Rua Doutor Costa Junior, 356 Água Branca — CEP 05002-000, São Paulo, SP, Brasil. E-mail: mvpo@gvmail.br.

*** Professor e coordenador do Programa de Mestrado e Doutorado em Administração Pública e Governo da Eaesp/FGV. Doutor em ciência política pela USP. Endereço: Avenida Nove de Julho, 2029 — Bela Vista — CEP 01313-902, São Paulo, SP, Brasil. E-mail: fabrucio@fgvsp.br.
} 
Este artigo estuda o formato e o funcionamento dos mecanismos de controle e accountability das agências reguladoras, ressaltando suas similaridades e distinções. Suas observações permitem abrir novas frentes de investigação para explicar as diferenças e semelhanças encontradas, tais como a influência da burocracia no processo e os contextos histórico e político de cada setor. $\mathrm{O}$ artigo analisa a formatação prevista legalmente para os dispositivos que proporcionam maior accountability às agências reguladoras, como a ouvidoria, as consultas públicas e os conselhos, e verifica indicadores de seu funcionamento efetivo, de forma a avaliar se a aparente uniformidade institucional dos órgãos reflete-se em uniformidade de procedimentos e de resultados. Por fim, aponta alguns impactos que o modelo institucional das agências reguladoras provoca na accountability do Estado brasileiro.

\section{Design and operation of the Brazilian regulatory agencies' control and accountability mechanisms: similarities and differences}

This article studies the design and operation of the regulatory agencies' control and accountability mechanisms, underlining their similarities and differences. Its observations open new investigation fronts for the explanation of the differences and similarities found, such as the influence of bureaucracy on the process and each sector's historical and political context. The article analyzes the design determined by legislation for mechanisms that provide the regulatory agencies with more accountability, such as the ombudsman department, public consultations and councils, and assesses the indicators of their effectiveness, in order to verify if the apparent institutional uniformity of the agencies corresponds to the uniformity of procedures and results. Finally, it points out some of the impacts of the regulatory agencies' institutional model on the accountability of the Brazilian state.

\section{Introdução}

A maior complexidade do Estado moderno, com a proliferação de agências reguladoras e executivas em diversos países levando ao fenômeno da "agencificação" (Pollitti, 2002), traz novos desafios à democracia, ao criar domínios controlados por burocracias técnicas com pouca ou nenhuma responsabilização pública (Oslak, 1998). Nesse sentido, a discussão sobre a accountability vem dar novas dimensões à democracia. Este artigo traz essa discussão para as agências reguladoras brasileiras, surgidas em um contexto de mudança e de reforma do Estado brasileiro, com as privatizações e instalação de órgãos em novos formatos institucionais.

O artigo está dividido metodologicamente da seguinte forma: primeiramente a reforma do Estado realizada durante o governo Fernando Henrique 
Cardoso é contextualizada historicamente, onde ressaltam-se alguns legados importantes como o insulamento burocrático, o corporativismo e o clientelismo. A seguir, faz-se um breve relato da implantação de agências reguladoras no período 1996-2002 e as possíveis motivações para a escolha desse formato institucional.

Os próximos itens delimitam os objetos de estudo. Apresentam-se as definições de controle e accountability que o artigo operacionalizará, assim como a limitação dos aspectos a serem verificados no modelo básico das agências reguladoras brasileiras e os critérios utilizados para a seleção dos órgãos pesquisados. Também é feita uma breve contextualização dos setores onde as agências estudadas atuam, de forma a permitir algumas inferências sobre como isso afetou o seu desenho e funcionamento. $\mathrm{O}$ artigo é finalizado apresentando os resultados encontrados e as conclusões sobre as observações verificadas.

\section{As reformas administrativas brasileiras}

As primeiras ações voltadas de maneira sistemática em busca de profissionalização da burocracia brasileira foram dadas na década de 1930 pelo varguismo. No entanto, em vez da instauração de um sistema meritocrático para todo o aparato estatal e de instrumentos democráticos de controle das estruturas burocráticas, foi criado um modelo híbrido e muitas vezes contraditório, no qual conviviam o clientelismo, arranjos de corporativismo estatal e o insulamento de setores da burocracia em relação aos conflitos políticos (Nunes, 1997). Houve um princípio de meritocracia, com a instalação do Departamento de Administração do Serviço Público (Dasp). Com isso queria-se contornar as relações problemáticas entre as diversas forças políticas existentes ao mesmo tempo em que se tentava avançar na modernização do país. Nessa estrutura, a responsabilização da administração pública perante os cidadãos era pouco significativa.

Os projetos de desenvolvimento e os arranjos montados no varguismo prosseguiram nas décadas seguintes. Na década de 1960, o Estado brasileiro passou pelo regime militar, que levou, em termos de administração pública, a um maior insulamento da burocracia em relação a qualquer tipo de accountability, ao mesmo tempo em que ocorreu uma grande expansão da intervenção estatal. Nesse contexto, desenvolveu-se uma visão tecnocrática de atuação estatal, bem como criaram-se fortes relações entre a burocracia com setores privados sem que houvesse transparência nesse arranjo, conformando os denominados "anéis burocráticos" (Cardoso, 1975). A burocracia se preparou para exercer o seu papel em um Estado intervencionista, centralizador e com uma ideologia 
própria (Gouvêa, 1994:83), encontrando condições para desenvolver um comportamento autônomo em relação aos atores sociais.

O fim do regime militar, na década de 1980, trouxe de volta ao debate a democratização do Estado e de seu aparelho burocrático. De fato, foram criados vários mecanismos para a sociedade monitorar e cobrar o poder público, incorporados na Constituição de 1988, ainda que não tenham sido devidamente regulamentados e aplicados. Do ponto de vista da burocracia, o princípio do mérito tornou-se, pelo menos constitucionalmente, universal. Além do mais, formas de accountability horizontal e vertical fortaleceram-se, e a ação burocrática é, geralmente, mais transparente que nos períodos anteriores. Todavia, os legados do corporativismo e do insulamento continuaram influenciando o comportamento da burocracia e seu relacionamento com o sistema político e com a sociedade.

A primeira grande reforma administrativa do período democrático recente foi formulada durante o mandato do presidente Fernando Henrique Cardoso. O Plano Diretor da Reforma do Aparelho do Estado, preparado pelo então Ministério da Administração Federal e da Reforma do Estado (Mare), declarava como propósitos alterar as bases do Estado brasileiro, a fim de melhorar seu desempenho e democratizá-lo. Para isso atividades que não fossem consideradas essenciais deveriam ser repassadas à iniciativa privada e reguladas pelo Estado, ao mesmo tempo em que se implantaria a "administração pública gerencial". Nessa lógica destacavam-se a criação de agências autônomas, divididas em reguladoras e executivas. O plano diretor focava essas últimas.

As principais ações previstas no plano da accountability eram a participação de usuários; a utilização de contratos de gestão como forma de responsabilização por resultados; adoção de mecanismos de controle social nos serviços locais e o aumento da transparência na implementação das ações do governo, possibilitando seu acompanhamento e avaliação. As noções de controle e accountability ficariam, dessa forma, estreitamente ligadas a avaliação e publicidade dos resultados e informações dos órgãos, assim como na institucionalização de mecanismos de participação.

Essas diretrizes estão, de alguma forma, presentes na criação das agências reguladoras. Devemos lembrar que, além das linhas gerais do plano diretor, houve em maio de 1996 uma recomendação do Conselho da Reforma do Estado para a Construção do Marco Legal dos Entes Reguladores, que indicava diretrizes mais específicas para esses órgãos. Todavia, não houve processo coordenado de mudança do aparelho estatal, da reforma regulatória e das privatizações que gerasse uma concepção explícita da natureza e da operacionalização do Estado regulador (Abranches, 1999). Cada área específica já es- 
tava discutindo a privatização e a regulação, e pouco dialogava com o Mare nesse sentido. Isso acabou por tornar o processo fragmentado, sendo fortemente conduzido pelas concepções dos ministérios e pela burocracia de cada setor, e não por uma diretriz orientadora geral, o que impactou o formato e o funcionamento das agências criadas.

\section{A criação e implementação das agências reguladoras}

A criação do modelo regulador nos anos FHC pode ser, grosso modo, dividida em três gerações (Santana, 2002; Martins, 2002). Na primeira, estabelecida entre 1996 e 1997, estão as agências reguladoras relacionadas com a privatização e a quebra do monopólio do Estado naqueles setores, englobando a Agência Nacional de Energia Elétrica (Aneel), a Agência Nacional de Telecomunicações (Anatel) e a Agência Nacional de Petróleo (ANP). O formato institucional, com diretores escolhidos pelo presidente, aprovados pelo Senado e gozando de mandato fixo eram elementos fundamentais para a credibilidade dos investidores em uma estabilidade das regras. A preocupação maior, nesses casos, era econômica: além da obtenção de recursos para pagamento da dívida pública, o argumento essencial relacionava-se à ausência de recursos governamentais para investimentos nesses setores. Nesse sentido, é interessante lembrar que o desenho da Anatel contou com a participação de consultorias internacionais.

A segunda leva está mais relacionada à busca de melhor eficiência e modernização do aparelho de Estado, surgindo no período 1999/2000. Eram setores mais competitivos nos quais buscava-se resguardar o interesse dos cidadãos em relação a determinados setores de mercado já existentes - situação diferente da anterior, quando se estava repassando atividades estatais para a iniciativa privada. Duas agências fazem parte dessa geração: a Agência Nacional de Vigilância Sanitária (Anvisa) e a Agência Nacional de Saúde Suplementar (ANS), ambas ligadas ao Ministério da Saúde. Martins (2002) e Costa (2002) indicam que o modelo de agências reguladoras começou a ser utilizado devido às dificuldades para a implementação das agências executivas previstas no plano diretor.

Já a terceira geração (2001/02) apresenta uma grande mistura de finalidades e áreas de atuação. Aqui, apenas a Agência Nacional dos Transportes Terrestres (ANTT) e a Agência Nacional dos Transportes Aquaviários (Antaq) podem ser consideradas de natureza reguladora, pelo tipo de atividades desenvolvidas. Outros casos, como a Agência Nacional de Águas (ANA) e a Agência Nacional do Cinema (Ancine), mostram a perda do referencial 
de regulação de mercados. Tais experiências aproximam-se daquilo que Pollitt (2002) classificou como mimetismo, fenômeno marcante nas reformas do Estado da década de 1990. Copiavam-se simplesmente instituições em contextos e problemas muito diferentes. Esse mimetismo pode ser verificado no Brasil, principalmente no que se refere às agências reguladoras estaduais.

Em setembro de 2005, no governo do presidente Luiz Inácio Lula da Silva, foi criada a Agência Nacional de Aviação Civil (Anac), depois de uma longa tramitação desse assunto no Congresso Nacional. Esta foi a mais recente agência criada nesse formato no país, sendo instalada apenas em 2006.

Essas observações encaixam-se nas possíveis motivações elencadas por Mueller e Pereira (2002:66) para a criação de agências reguladoras: a busca de flexibilidade administrativa além da existente na estrutura do serviço público; dar incentivos aos reguladores para que eles se especializem e diminuam as incertezas dos resultados de cada setor; a busca de blame-shifting, transferindo parcialmente à agência a culpa por medidas politicamente impopulares em determinado setor; e por fim a necessidade de credibilidade regulatória, ou seja, a estabilidade das regras, resguardando-as de ações oportunistas de políticos eleitos. Seguindo essa tipologia, as agências de primeira geração estão mais claramente relacionadas com a quarta motivação, enquanto as de segunda dão maior ênfase às duas primeiras. A terceira geração apresenta uma mistura mais complexa de motivações.

Assim temos uma diversidade de órgãos que atuam em áreas e com tipos de regulação distintos, desde a regulação econômica, a social e inclusive o incentivo, o que escapa do conceito de regulação. Assume-se aqui a distinção normalmente estabelecida entre regulação econômica - que se refere a preços, tarifas, condições de entrada e saída em mercados - e a regulação social relativa a temas como saúde e segurança (Meier, 1985:3).

O quadro 1 mostra as agências reguladoras criadas durante o mandato de Fernando Henrique Cardoso e de Luiz Inácio Lula da Silva.

É importante lembrar que algumas leis de criação foram alteradas por medidas provisórias, como os casos da ANS, Anvisa, ANTT e Antaq. A medida provisória de criação da Ancine foi alterada pela Lei $\mathrm{n}$ - 10.454, de 13 de maio de 2002. Houve ainda alterações por outros dispositivos legais, tais como a Lei $n^{0}$ 9.986, de 18 de julho de 2000, que alterou a gestão de recursos humanos das agências criadas anteriormente à sua promulgação. 


\begin{tabular}{|c|c|c|c|c|}
\hline \multicolumn{5}{|c|}{$\begin{array}{c}\text { Quadro } 1 \\
\text { Relação das agências reguladoras }\end{array}$} \\
\hline Agência & $\begin{array}{l}\text { Ministério } \\
\text { relacionado }\end{array}$ & $\begin{array}{l}\text { Lei de } \\
\text { criação no }\end{array}$ & $\begin{array}{l}\text { Decreto de } \\
\text { instalação } n^{0}\end{array}$ & $\begin{array}{l}\text { Tipo de } \\
\text { regulação }\end{array}$ \\
\hline $\begin{array}{l}\text { Agência Nacional de } \\
\text { Energia Elétrica (Aneel) }\end{array}$ & Minas e Energia & $\begin{array}{l}\text { 9.427, de } 26 \text { de } \\
\text { dezembro de } 1996\end{array}$ & $\begin{array}{l}2.335, \text { de } 6 \text { de } \\
\text { outubro de } 1997\end{array}$ & Econômica \\
\hline $\begin{array}{l}\text { Agência Nacional de } \\
\text { Telecomunicações (Anatel) }\end{array}$ & Comunicações & $\begin{array}{l}\text { 9.472, de } 16 \text { de } \\
\text { julho de } 1997\end{array}$ & $\begin{array}{l}2.338 \text {, de } 7 \text { de } \\
\text { outubro de } 1997\end{array}$ & Econômica \\
\hline $\begin{array}{l}\text { Agência Nacional do } \\
\text { Petróleo (ANP) }\end{array}$ & Minas e Energia & $\begin{array}{l}9.478, \text { de } 6 \text { de } \\
\text { agosto de } 1997\end{array}$ & $\begin{array}{l}2.455, \text { de } 14 \text { de } \\
\text { janeiro de } 1998\end{array}$ & Econômica \\
\hline $\begin{array}{l}\text { Agência Nacional de } \\
\text { Vigilância Sanitária (Anvisa) }\end{array}$ & Saúde & $\begin{array}{l}\text { 9.782, de } 26 \text { de } \\
\text { janeiro de } 1999\end{array}$ & - & Social \\
\hline $\begin{array}{l}\text { Agência Nacional de } \\
\text { Águas (ANA) }\end{array}$ & Meio Ambiente & $\begin{array}{l}\text { 9.984, de } 17 \text { de } \\
\text { julho de } 2000\end{array}$ & $\begin{array}{l}\text { 3.692, de } 19 \text { de } \\
\text { dezembro de } 2000\end{array}$ & $\begin{array}{l}\text { Social } \\
\text { (ambiental) }\end{array}$ \\
\hline $\begin{array}{l}\text { Agência Nacional de } \\
\text { Saúde Suplementar (ANS) }\end{array}$ & Saúde & $\begin{array}{l}9.961, \text { de } 28 \text { de } \\
\text { janeiro de } 2000\end{array}$ & $\begin{array}{l}3.327 \text {, de } 5 \text { de } \\
\text { janeiro de } 2000\end{array}$ & $\begin{array}{l}\text { Econômica } \\
\text { e social }\end{array}$ \\
\hline $\begin{array}{l}\text { Agência Nacional de } \\
\text { Transportes Aquáticos } \\
\text { (Antaq) }\end{array}$ & Transportes & $\begin{array}{l}10.233 \text {, de } 5 \text { de } \\
\text { junho de } 2001\end{array}$ & $\begin{array}{l}4.122, \text { de } 13 \text { de } \\
\text { fevereiro de } 2002\end{array}$ & Econômica \\
\hline $\begin{array}{l}\text { Agência Nacional } \\
\text { de Transportes } \\
\text { Terrestres (ANTT) }\end{array}$ & Transportes & $\begin{array}{l}10.233 \text {, de } 5 \text { de } \\
\text { junho de } 2001\end{array}$ & $\begin{array}{l}4.130, \text { de } 13 \text { de } \\
\text { fevereiro de } 2002\end{array}$ & Econômica \\
\hline $\begin{array}{l}\text { Agência Nacional do } \\
\text { Cinema (Ancine) }\end{array}$ & $\begin{array}{l}\text { Desenvolvimento, } \\
\text { Indústria e } \\
\text { Comércio } \\
\text { Exterior }\end{array}$ & $\begin{array}{l}\text { MP n-2.228, de } 6 \\
\text { de setembro de } \\
2001\end{array}$ & - & $\begin{array}{l}\text { Social } \\
\text { (incentivo) }\end{array}$ \\
\hline $\begin{array}{l}\text { Agência Nacional de } \\
\text { Aviação Civil (Anac) }\end{array}$ & Defesa & $\begin{array}{l}11.182 \text {, de } 27 \text { de } \\
\text { setembro de } 2005\end{array}$ & $\begin{array}{l}5.731 \text {, de } 20 \text { de } \\
\text { março de } 2006\end{array}$ & Econômica \\
\hline
\end{tabular}

\section{Definições de controle e accountability e possíveis mecanismos}

Uma burocracia completamente autônoma, como todo poder auto-referenciado, traz riscos à sociedade e à democracia. A discussão ganha novos contornos com os processos de reforma do Estado, nos quais uma das principais marcas foi o repasse da execução de atividades antes estatais a entes privados e, nesse contexto, instrumentos de accountability precisaram ser repensados. Além disso, cada vez mais o controle e a accountability do Estado são inseridos num contexto de ampliação dos espaços democráticos, que precisa chegar aos cidadãos (Clad, 2000). 
Apesar de existirem áreas superpostas entre controle e accountability, podemos estabelecer uma diferenciação operacional básica entre os termos. Para o controle assumimos a definição de Dahl e Lindblom (1971) que o consideram como a capacidade de um ator em fazer que outro atenda às demandas daquele, pela imposição de restrições, penalidades e incentivos. A accountability é um conceito mais amplo, que inclui a existência de condições para os cidadãos participarem da definição e avaliação das políticas públicas, premiando ou punindo os responsáveis (Clad, 2000). Nessas condições deve constar a disponibilidade de informações sobre a atuação dos governos e seus resultados, bem como a existência de instituições que permitam contestar as ações do poder público. Assim, controle e accountability não são sinônimos, sendo o primeiro um dos componentes do segundo, embora sejam, num regime democrático, indissociavelmente ligados, porque não há efetivação da accountability sem a utilização de instrumentos institucionais de controle.

A discussão também passa pela definição de três aspectos fundamentais: o objeto sobre o qual se exercem, quem o exerce e como o faz. Dentro de um sistema político presidencialista como o brasileiro, com a divisão institucional de poderes, controle e accountability devem ser forçosamente baseados na interação entre os diversos atores, os poderes Executivo, Legislativo e Judiciário. Além disso, inclui-se a sociedade civil que, em um contexto de regulação, pode ser dividida entre os grupos econômicos regulados e os grupos sociais não-econômicos, que, segundo Majone (1999), têm obtido destaque no Estado regulador. Contudo, deve ficar claro que quaisquer que sejam os mecanismos, eles devem ser rastreáveis, direta ou indiretamente, pelos cidadãos, senhores últimos da legitimidade em um regime democrático.

Existe, portanto, um mecanismo complexo de accountability entre os diversos atores. Para uma noção dessa complexidade podemos dar alguns exemplos da interação múltipla entre os atores. Em uma linha direta a sociedade civil monitora os políticos, que monitoram as agências e estas, por sua vez, regulam as empresas. O Judiciário permite que um ator interfira diretamente em outro, como os consumidores nas empresas. Os consumidores e grupos da sociedade civil sofrem efeitos das empresas e informam tanto ao regulador quanto aos políticos desses resultados. Grupos econômicos e sociais atuam diretamente sobre a agência. Executivo e Legislativo atuam um sobre o outro.

Neste artigo nos concentramos na avaliação dos mecanismos de disponibilização de informação e de participação de diversas agências reguladoras, ou seja, no aspecto da prestação de contas. Tais mecanismos, ainda que não garantam a execução da accountability, proporcionam aos cidadãos, regulados e políticos, condições de aferir o comportamento e os resultados da ação dos órgãos, atuando na sua responsabilização. O controle, aspecto igualmente fundamental para a efetivação da accountability, que pode se dar por diversas vias - judiciais, políticas, constrangimentos etc. —, não foi incluído no escopo deste artigo. 


\section{Desenho institucional básico das agências reguladoras brasileiras}

Parte da literatura nacional sobre as agências reguladoras federais trata os órgãos como se houvesse um modelo claro e definido sobre a sua configuração institucional. Ainda que não exista um modelo geral, de fato, algumas características em comum podem ser destacadas, como no quadro 2 .

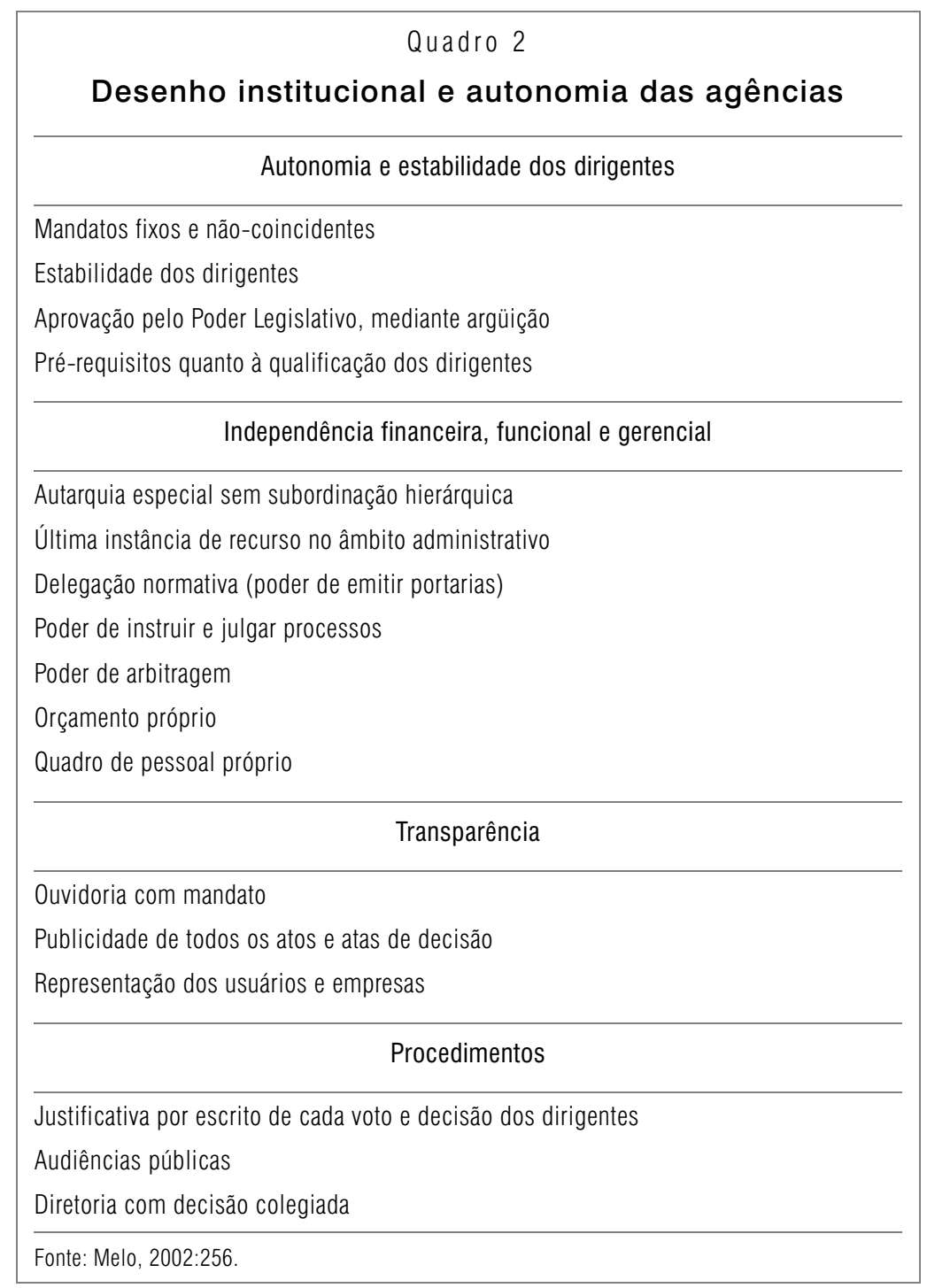

RaP Rio de Janeiro 40(4):679-98, Jul./Ago. 2006 
Apesar de não haver uma orientação de como deveria ser a configuração do Estado regulador após a privatização e a concessão de serviços públicos, nem diretrizes orientadoras articuladas para o desenho institucional das agências reguladoras, houve, de modo geral, uma uniformização desses órgãos. À primeira vista essa uniformidade chama a atenção, pois são áreas com trajetórias, configurações políticas e problemas peculiares, portanto seria de se esperar uma maior diversidade institucional, na linha indicada por Mueller e Pereira (2002).

Por exemplo, em relação ao ambiente político em que uma agência governamental pode estar inserida devido aos grupos que serão afetados pela sua ação, Wilson (1989) define simplificadamente quatro contextos. No primeiro caso há um grupo dominante favorável aos objetivos da agência, resultando em uma política clientelista em que a maioria dos benefícios de um programa vai para um pequeno grupo, mas os custos são dispersos por um grupo grande de atores. No segundo caso há um grupo dominante hostil aos objetivos da agência, o que a leva a ter uma política empreendedora, buscando apoio de grupos sociais ou de políticos para poder realizar a sua missão. O terceiro contexto surge quando há equilíbrio entre dois ou mais grupos rivais em conflito em relação aos objetivos da agência, o que ajudaria a manter um grau de autonomia e discricionariedade da agência. Por fim, em algumas áreas os interesses podem ser fragmentados pelo fato de tanto benefícios quanto custos terem baixo valor per capita, o que faz com que não existam grupos continuamente organizados, levando à necessidade de uma ação política que aglutine interesses e forças dispersos. No caso brasileiro acrescenta-se o fato de os setores onde houve privatizações mudarem a configuração, com a entrada de investidores internacionais e com a mudança de posição de antigos burocratas estatais, que passaram para essas empresas privadas.

A construção das agências reguladoras de cada área teve dinâmica e motivações próprias. Os problemas do setor, os desejos e negociações dos representantes políticos, a existência de grupos e interesses organizados afetam a configuração institucional e as regras a que uma agência pode estar submetida. A argumentação deste artigo mostra que essa uniformidade é, em grande medida, aparente e esconde diferenças significativas no funcionamento das agências. Assim, a diversidade dos setores já estaria incorporada no funcionamento, mais que no desenho, das agências, o que matiza a argumentação de Mueller e Pereira (2002:68) no sentido de que as diferenças entre os reguladores serão provocadas depois da sua instalação devido à ação dos atores políticos, sociais e econômicos envolvidos em cada setor. 


\section{Seleção dos objetos de pesquisa}

Para a avaliação foi selecionada uma amostra das agências existentes. De forma a mostrar que mesmo com atuações similares os órgãos podem assumir diferenças significativas, foram selecionadas agências que tivessem atuações em domínios similares e sujeitas a configurações assemelhadas de interesses. A lógica de seleção foi a de procurar agências que atuassem no estabelecimento de padrões e referências técnicas para as empresas reguladas, proporcionassem intervenções econômicas no mercado que afetassem diretamente a alocação de renda dos stakeholders no setor (tais como tarifas, reajustes e concorrência) e cujos objetos de regulação afetassem diretamente os usuários finais, os cidadãos, de forma que eles tivessem interesse em monitorar as agências.

Assim, com exceção da Ancine, todas as agências atuam no estabelecimento de padrões técnicos a serem seguidos pelos regulados o que exclui essa instituição. O estabelecimento de padrões técnicos afeta a lucratividade das empresas, que certamente terão que investir para atendê-los, mas o critério adotado de atuação econômica exclui a ANA e a Anvisa da avaliação. Já pelo critério de afetar diretamente os usuários finais, excluímos a $\mathrm{ANP}^{1}$ e a Antaq. A Anac, por ser de instalação muito recente, ainda não possui dados históricos suficientes para uma análise comparativa.

Dessa forma, avaliamos quatro agências: Anatel, Aneel, ANS e ANTT. Essa amostra apresenta duas peculiaridades interessantes: as agências são de diferentes etapas de regulação (com exceção da Anatel e Aneel) e são vinculadas a ministérios distintos. A primeira característica permite inferir se houve algum processo de aprendizado ou mimetismo na concepção dos órgãos, como indicado pela literatura. Por sua vez, a segunda permite verificar se os órgãos concebidos por diferentes burocracias setoriais assumiram conformações institucionais diversas.

Para a comparação, tomamos como base os requisitos apontados por Melo (2002), constantes do quadro 2. Esses itens referem-se diretamente à configuração institucional das agências e também à sua accountability, visto que proporcionam alguma condição para que os stakeholders possam monitorar os órgãos e eventualmente impor-lhes constrangimentos ou recompensas. O formato desses incentivos não é objeto deste artigo.

\footnotetext{
${ }^{1}$ A ANP monitora a qualidade de combustíveis distribuídos nos postos. Contudo essa é a única atuação dela que afeta o usuário final e é uma das atividades que recebe menos recursos da agência se comparadas a outras como a concessão de licenças de exploração.
} 
Para exemplificar a importância desses dispositivos podemos verificar algumas situações. A realização de consultas públicas, com a disponibilização das manifestações enviadas pelos diversos atores e a avaliação da agência sobre as mesmas, permite esclarecer os conflitos de posição entre eles e constrange a discricionariedade da agência. A disponibilidade de atas e relatórios aumenta a informação disponível, que pode ser usada até judicialmente por atores que se sentirem prejudicados pelas decisões do órgão.

No primeiro momento, verificamos a existência daqueles requisitos nas leis de criação, nos decretos de implantação e nos regulamentos internos das agências selecionadas, assim como a sua configuração.

Em uma segunda etapa procuramos indicadores do funcionamento desses mecanismos, de forma a clarificar possíveis diferenças operacionais entre as agências estudadas. Foram pesquisados os sites das agências para a verificação da realização de consultas públicas, disponibilidade de documentos, relatórios, entre outros. Foram incluídos alguns fatores não listados por Melo (2002), mas relevantes para a prestação de contas dos órgãos, como os contratos de gestão e os relatórios administrativos e setoriais eventualmente disponíveis.

\section{Breve panorama dos setores estudados: energia elétrica, telecomunicações, saúde suplementar e transportes terrestres}

Esta seção traz uma descrição muito breve da configuração de cada um dos setores, assim como de sua evolução histórica. Esses elementos são relevantes para tentar compreender as possíveis diferenças entre as agências estudadas.

A burocracia que formou a Aneel, inclusive o seu primeiro presidente, originou-se no Departamento Nacional de Águas e Energia Elétrica (DNAEE), órgão criado em 1968. O seu regimento interno (Portaria no 234, de 17 de fevereiro de 1977 - Ministério das Minas e Energia) definia entre suas atribuições o "planejamento, coordenação e execução dos estudos hidrológicos em todo o território nacional; pela supervisão, fiscalização e controle dos aproveitamentos das águas que alteram o seu regime; bem como pela supervisão, fiscalização e controle dos serviços de eletricidade". Segundo o estudo de Nunes (2005), a Aneel foi sendo formatada ao longo das discussões sobre a estruturação do setor, da sua legislação e da lei da própria agência. A princípio pensavase apenas em um reforço na estrutura do DNAEE, que gradativamente foi se transformando em uma agência reguladora, em processo que contou com a participação ativa do Congresso. Esse aprendizado pode explicar o fato de o decreto de instalação vir cerca de um ano após a promulgação da lei. Enquanto isso alguns estados, como o Rio de Janeiro, já privatizavam suas empresas de distribuição de energia elétrica, antes mesmo de um marco legal e da existência da agência. Temos então um setor com o marco legal incompleto e com a entrada de investidores privados, substituindo a antiga posse estatal. 
O processo de telecomunicações foi mais estruturado. Ainda que não houvesse, em princípio, um desenho claro do que seria a agência, houve um sentido mais claro ao longo do processo de estruturação do arcabouço legal e regulatório (Nunes, 2005). Nessa área houve a necessidade de emenda constitucional (EC $n^{0}$ 8, de 15 de agosto de 1995) para permitir a exploração das telecomunicações por empresas privadas. Em 1997 foi aprovada a chamada Lei Geral das Telecomunicações (Lei no 9.472, de 16 de julho de 1997), que definia o marco regulatório do setor e a Anatel, preparando o terreno para a privatização (Pó, 2004). O setor passou, então, por uma grande mudança: a burocracia estatal anterior, que estava no sistema Telebrás, foi dividida entre o regulador e as empresas privadas, ao mesmo tempo em que grandes investimentos ingressaram na área.

O setor de saúde suplementar (planos de saúde privados) remonta à década de 1950, por meio de fundos assistenciais de empresas públicas. O mercado aproxima-se mais do formato atual no final da década de 1970, com a criação de convênios médicos de empresas privadas e de redes de prestação de serviços médicos e, no final dos anos 1980, com a entrada dos seguros-saúde. O setor ficava cada vez mais complexo e aumentavam os conflitos entre usuários e empresas, regrados parcialmente pelo Código de Defesa do Consumidor promulgado em 1991. Em 4 de junho de 1998 é aprovada a Lei $n^{0} 9.656$ que, alterada por 44 medidas provisórias, forneceu a base legal do setor. A lei também ajudou a clarear as responsabilidades de regulação na área, que eram divididas entre os ministérios da Fazenda, Saúde e Justiça. A ANS é criada pela MP no 2.012, de 30 de dezembro de 2004, transformada na Lei no 9.961 , de 28 de janeiro de 2000, alterada diversas vezes por medidas provisórias. A agência incorporou mecanismos existentes em estruturas anteriores, como a Câmara de Saúde Suplementar, instância ligada anteriormente ao Conselho de Saúde Suplementar (Consu). Em termos de atores não houve entradas ou mudanças de posição, o mercado sempre foi privado. Houve, sim, uma alteração no foco da ação dos stakeholders, que se concentraram sobre a ANS após a sua criação (Pó, 2004). Deve-se ainda ter em mente que a saúde suplementar interage com a saúde pública, sendo assim um elemento de interesse para os atores políticos, tanto que gerou uma CPI em 2003 na Câmara dos Deputados.

Os transportes terrestres enfrentam uma questão federativa relevante. Há rodovias e ferrovias de posse exclusiva dos três níveis federativos, que podem concedê-las à iniciativa privada. O transporte nessas vias, de cargas ou pessoas, também enfrenta as mesmas questões. A regulação do setor é então necessariamente dividida entre União, estados e municípios. Em nível federal a regulação era feita internamente no Ministério dos Transportes, que criou duas agências reguladoras separadas (ANTT e Antaq). Assim como no caso da ANS, aqui não houve mudança de posição entre os atores (empresas, governo e usuários), apenas uma mudança no centro da ação, que passa a ser a ANTT. 


\section{Resultados e observações}

Os resultados estão apresentados em dois quadros. O quadro 3 mostra os requisitos previstos no modelo geral das agências, segundo suas leis e decretos. Já o quadro 4 apresenta indicadores qualitativos e quantitativos de funcionamento desses dispositivos.

\begin{tabular}{|c|c|c|c|c|}
\hline Previs & $\begin{array}{r}\text { são legal de di } \\
\text { das }\end{array}$ & $\begin{array}{l}\text { Quadro } 3 \\
\text { ispositivos pre } \\
\text { agências reg }\end{array}$ & $\begin{array}{l}\text { evistos no mod } \\
\text { guladoras }\end{array}$ & o básico \\
\hline Dispositivo & Anatel & Aneel & ANS & ANTT \\
\hline $\begin{array}{l}\text { Diretoria } \\
\text { colegiada }\end{array}$ & $\begin{array}{l}\text { Cinco membros } \\
\text { aprovados pelo } \\
\text { Senado; mandatos } \\
\text { não-coincidentes } \\
\text { de cinco anos }(\mathrm{L})\end{array}$ & $\begin{array}{l}\text { Cinco membros } \\
\text { aprovados pelo } \\
\text { Senado; mandatos } \\
\text { não-coincidentes } \\
\text { de quatro anos (L) }\end{array}$ & $\begin{array}{l}\text { Até cinco membros } \\
\text { aprovados pelo } \\
\text { Senado; mandatos } \\
\text { não-coincidentes } \\
\text { de três anos }(\mathrm{L})\end{array}$ & $\begin{array}{l}\text { Cinco membros } \\
\text { aprovados pelo } \\
\text { Senado; mandatos } \\
\text { não-coincidentes } \\
\text { de quatro anos (L) }\end{array}$ \\
\hline $\begin{array}{l}\text { Disponibilidade } \\
\text { de atas do } \\
\text { conselho } \\
\text { diretor }\end{array}$ & Obrigatória (L) & $\begin{array}{l}\text { As reuniões } \\
\text { poderão ser } \\
\text { públicas, a critério } \\
\text { da diretoria (D) }\end{array}$ & Não consta & Obrigatória (L) \\
\hline Conselhos & $\begin{array}{l}\text { Conselho } \\
\text { consultivo: } 12 \\
\text { membros com } \\
\text { mandato de três } \\
\text { anos (L) }\end{array}$ & Não previsto & $\begin{array}{l}\text { Câmara de Saúde } \\
\text { Suplementar: } 34 \\
\text { membros (L) }\end{array}$ & Não previsto \\
\hline Ouvidoria & $\begin{array}{l}\text { Nomeado pelo } \\
\text { presidente da } \\
\text { República, mandato } \\
\text { de dois anos. } \\
\text { Obrigação de } \\
\text { produzir relatórios } \\
\text { semestrais }(\mathrm{L})\end{array}$ & $\begin{array}{l}\text { Exercida por um } \\
\text { dos diretores }(\mathrm{L})\end{array}$ & $\begin{array}{l}\text { Lei prevê existência; } \\
\text { mandato, nomeação } \\
\text { pelo presidente da } \\
\text { República e produção } \\
\text { de relatórios são } \\
\text { definidos pelo decreto }\end{array}$ & $\begin{array}{l}\text { Nomeado pelo } \\
\text { presidente da } \\
\text { República, mandato } \\
\text { de três anos }(\mathrm{L})\end{array}$ \\
\hline $\begin{array}{l}\text { Realização } \\
\text { de consultas } \\
\text { e audiências } \\
\text { públicas }\end{array}$ & $\begin{array}{l}\text { Minutas de atos } \\
\text { normativos devem } \\
\text { ser submetidas e } \\
\text { críticas e sugestões } \\
\text { devem ficar } \\
\text { disponíveis (L) }\end{array}$ & $\begin{array}{l}\text { Para processo } \\
\text { decisório que } \\
\text { afetar direitos dos } \\
\text { agentes econômicos } \\
\text { ou consumidores }(\mathrm{L})\end{array}$ & $\begin{array}{l}\text { Poderá ser realizada } \\
\text { a critério da } \\
\text { diretoria (D) } \\
\text { ) }\end{array}$ & $\begin{array}{l}\text { Para processo } \\
\text { decisório que afetar } \\
\text { direitos dos agentes } \\
\text { econômicos ou } \\
\text { consumidores }(\mathrm{L})\end{array}$ \\
\hline $\begin{array}{l}\text { Contrato de } \\
\text { gestão }\end{array}$ & Não previsto & Previsto (L) & $\begin{array}{l}\text { Previsto, o } \\
\text { descumprimento pode } \\
\text { acarretar demissão do } \\
\text { diretor-presidente }(\mathrm{L})\end{array}$ & Não previsto \\
\hline
\end{tabular}

RAP Rio de Janeiro 40(4):679-98, Jul./Ago. 2006 
No quadro foram descartados os itens referentes à "Independência financeira, funcional e gerencial", dado que eles são idênticos às agências estudadas e estão todos previstos na lei. As decisões do conselho diretor são colegiadas e tomadas por maioria.

Aqui já se pode notar algumas diferenças entre os órgãos. A Anatel possui maior formalização legal de seus procedimentos que as demais agências. A legislação das agências ligadas à regulação de concessões e infra-estrutura (Anatel, Aneel e ANTT) é mais rígida em relação a procedimentos de transparência, como consultas públicas e disponibilidade de atas, assim como os seus diretores possuem mandatos mais longos. A configuração institucional da ANS possui maior flexibilidade do ponto de vista da interferência do Poder Executivo, já que, além da possibilidade de demissão pelo descumprimento do contrato de gestão, itens como a ouvidoria e a realização de consultas públicas estão previstos apenas no decreto, que é um instrumento legal menos estável.

É necessário um estudo aprofundado para determinar as causas dessas diferenças, mas o fato de se tratarem de setores privatizados ou concedidos parece ter sido um fator determinante, dada a necessidade de credibilidade regulatória.

A construção do quadro 4 merece uma explicação detalhada, pois foram tomadas algumas medidas para permitir a comparação e as conclusões derivadas.

A compilação das resoluções e audiências exigiu cuidados especiais. As agências possuem padrões e nomenclaturas diferenciadas na emissão dos atos normativos, assim como o mesmo tipo de ato pode incluir desde resoluções sobre métodos de cálculo de tarifas até a nomeação de gerentes internos.

Para as resoluções, foram primeiramente compilados os atos que as próprias agências consideravam regulatórios, ou seja, pudessem afetar de alguma forma a dinâmica do mercado regulado, atingindo diretamente os interesses dos regulados e dos cidadãos, tais como o estabelecimento de padrões de qualidade, metodologias de cálculos de preços, direitos e deveres dos atores etc. Dessa forma os stakeholders teriam interesse em se manifestar antes da decisão da agência. Os atos foram analisados e excluíram-se aqueles que se referiam a ações administrativas operacionais (designação de cargos, regras de aquisição de bens, administração de recursos humanos...); alterações no regimento ou na estrutura de comissões internas da agência e que estipulavam metas ou medidas específicas para apenas uma empresa regulada. Esse último caso justifica-se pois a agência poderia fazer isso por meio de apenas um ou de vários atos. Esses atos foram chamados no quadro 4 de resoluções regulatórias. 


\begin{tabular}{|c|c|c|c|c|}
\hline \multicolumn{5}{|c|}{$\begin{array}{l}\text { Quadro } 4 \\
\text { Indicadores do funcionamento das agências }\end{array}$} \\
\hline Indicador & Anatel & Aneel & ANS & ANTT \\
\hline $\begin{array}{l}\text { Mês e ano de } \\
\text { instalação (decreto) }\end{array}$ & Outubro de 1997 & Outubro de 1997 & $\begin{array}{l}\text { Janeiro de } \\
2001\end{array}$ & $\begin{array}{l}\text { Fevereiro de } \\
2002\end{array}$ \\
\hline $\begin{array}{l}\text { Disponibilidade de atas } \\
\text { do conselho diretor }\end{array}$ & $\operatorname{Sim}$ & $\operatorname{Sim}$ & Sim & Não \\
\hline Relatórios administrativos & $\operatorname{Sim}$ & Sim & $\operatorname{Sim}$ & Não encontrado \\
\hline $\begin{array}{l}\text { Relatórios com } \\
\text { avaliações do setor } \\
\text { regulado } \\
\text { Média de reuniões } \\
\text { anuais do conselho } \\
\text { consultivo }\end{array}$ & $\begin{array}{l}\text { Alguns indicadores } \\
\text { no relatório } \\
\text { administrativo }\end{array}$ & $\begin{array}{l}\text { Dados espalhados } \\
\text { em diversos } \\
\text { relatórios }\end{array}$ & Não & $\begin{array}{l}\text { Sim, por tipo de } \\
\text { serviço regulado }\end{array}$ \\
\hline \multicolumn{5}{|c|}{ Ouvidoria } \\
\hline Houve vacância? & Sim & Não & $\operatorname{Sim}$ & Não-disponível \\
\hline Atribuições & $\begin{array}{l}\text { Avalia criticamente } \\
\text { a agência; o público } \\
\text { possui outro canal }\end{array}$ & $\begin{array}{l}\text { Atendimento } \\
\text { ao público }\end{array}$ & $\begin{array}{l}\text { Atendimento } \\
\text { ao público }\end{array}$ & $\begin{array}{l}\text { Atendimento ao } \\
\text { público, efetua } \\
\text { críticas e } \\
\text { sugestões }\end{array}$ \\
\hline $\begin{array}{l}\text { Relatórios } \\
\text { disponíveis }\end{array}$ & $\begin{array}{l}\text { Quatro, o último } \\
\text { é de dezembro } \\
\text { de } 2003\end{array}$ & $\begin{array}{l}\text { Apenas dados } \\
\text { estatísticos }\end{array}$ & $\begin{array}{l}\text { Estatísticas } \\
\text { de } \\
\text { atendimento } \\
\text { de } 2003\end{array}$ & Um, de 2003 \\
\hline \multicolumn{5}{|c|}{ Emissão de regulamentos } \\
\hline Total & 421 & 358 & 186 & 106 \\
\hline Resoluções regulatórias & 283 & 256 & 149 & 105 \\
\hline \multicolumn{5}{|c|}{ Consultas e audiências públicas } \\
\hline Total realizado & 472 & 214 & 21 & 31 \\
\hline $\begin{array}{l}\text { Sobre regulamentos } \\
\text { Índice consulta/ }\end{array}$ & 256 & 143 & 21 & 31 \\
\hline regulamento (\%) & 90,5 & 55,9 & 14,1 & 29,5 \\
\hline \multicolumn{5}{|c|}{ Manifestações enviadas às consultas e audiências } \\
\hline Íntegras disponíveis & $\operatorname{Sim}$ & $\operatorname{Sim}$ & Não & $\begin{array}{l}\text { Sim, consolidadas } \\
\text { em um relatório }\end{array}$ \\
\hline Resposta da agência & $\begin{array}{l}\text { Poucos casos, } \\
\text { muitas vezes } \\
\text { com atraso }\end{array}$ & $\begin{array}{l}\text { Eventualmente, } \\
\text { com mais } \\
\text { freqüência a partir } \\
\text { de } 2005\end{array}$ & Não & $\begin{array}{l}\text { Sim, consolidadas } \\
\text { em um relatório }\end{array}$ \\
\hline
\end{tabular}

RAP Rio de Janeiro 40(4):679-98, Jul./Ago. 2006 
As consultas e audiências públicas seguiram o mesmo padrão de compilação. Também foram excluídas as consultas que tratavam da apuração da qualidade de serviços prestados, cumprimento de metas pelas empresas reguladas específicas ou de aspectos muito específicos de empresas, pois o interesse é mais localizado e poderia falsear o índice geral de consultas/resoluções. ${ }^{2}$

Resguardados esses cuidados para evitar um falseamento dos resultados, o índice consultas/resoluções permite avaliar a transparência das agências na sua tomada de decisão, principalmente se combinado com a disponibilidade da íntegra das manifestações e da resposta da agência às mesmas. Aqui já podemos notar uma diferença significativa: enquanto a Anatel realiza audiências de forma corriqueira (como previsto na sua lei), as outras agências já não fazem isso com freqüência. O caso da ANS é o mais grave: além de ser um procedimento raro, a agência não dá transparência ao processo. Aneel e ANTT possuem índices intermediários que podem ser motivados pela natureza das resoluções emitidas, pois elas podem não ser do interesse de um número elevado de stakeholders. É necessária uma avaliação mais aprofundada da natureza substantiva das resoluções para esclarecer esse ponto.

A disponibilidade de relatórios também mostra o compromisso com a transparência, que nesse caso é razoavelmente assemelhado entre os órgãos. Aqui também é necessária uma avaliação aprofundada sobre a qualidade da informação.

A ouvidoria apresenta diferenças, principalmente no que se refere à Aneel. Nessa agência o ouvidor é um ombudsman, enquanto nas demais tratase de um canal de contato com o público. As vacâncias e o atraso dos relatórios apontam deficiências desse mecanismo em termos de prestação de contas à sociedade.

\footnotetext{
2 ANS: foram descontadas 17 resoluções referentes a mudanças no regimento interno e 20 com decisões consideradas administrativas. Aneel: foram excluídas da contagem 59 audiências referentes a processos de revisão tarifária, seis audiências sobre a qualidade do serviço de empresas e seis sobre a realização de convênios com empresas estaduais. Resoluções: subtraíram-se alterações no regimento interno (oito) e as administrativas/operacionais (três). Também foram excluídas as que estipulavam metas de indicadores de qualidade individual de energia (91), pois não houve consultas públicas individuais e essa ação poderia ter sido realizada com apenas uma resolução. No site da Aneel não foi possível efetuar a pesquisa sobre resoluções que já foram revogadas, o que pode ter levado à subestimação do total de resoluções emitidas. ANTT: a agência separa as resoluções consideradas regulatórias das demais, mas não dá nenhuma denominação específica para esse tipo de ato. Foi excluída uma resolução que tratava de alterações no regimento interno. Anatel: nos dados de resoluções foram excluídas as que se referiam a temas administrativos operacionais (oito), alterações no regimento interno (três), composição das comissões internas da agência (11) e alterações de planos básicos (115). Foram incluídas seis súmulas normativas. Nas consultas foram subtraídas as que trataram de questões administrativas operacionais (duas), alterações no regimento interno (três), as de alterações em planos básicos (179) e as referentes à averiguação da qualidade de prestação de serviço e de atendimento de metas das operadoras específicas (32).
} 
Os conselhos consultivos existentes na Anatel e na ANS merecem uma observação mais detalhada. Na primeira trata-se de um fórum para o qual os diretores prestam contas de ações da agência para a realização de debates, sem que necessariamente influencie os rumos da Anatel. Para a ANS, a Câmara de Saúde Suplementar (CSS), como pode ser verificado pelas atas disponíveis, é um órgão onde freqüentemente são discutidas as normas que a agência emitirá. Isso transforma a CSS em um fórum quase deliberativo, onde os atores se enfrentam em torno de posições assumidas como em uma disputa política. É possível que isso tenha sido herdado dos debates e fóruns que marcaram historicamente o setor. ${ }^{3}$ Nesse caso a ANS pode estar agindo numa forma de corporativismo burocrático, preocupando-se em prestar contas apenas aos atores representados na CSS, o que explicaria o baixo número de consultas públicas.

\section{Conclusões e observações finais}

Apesar de haver um modelo básico que permeia as agências reguladoras, é um equívoco partir do pressuposto que, a despeito dos contextos políticos e históricos das burocracias e dos setores, o formato institucional e de regras tenha levado as agências a se comportarem da mesma forma. A implantação de um modelo institucional não leva necessariamente a resultados semelhantes, como pode ser inferido dos resultados deste estudo.

Vários motivos podem ter levado as agências a mostrar tais diferenças. Entre eles estão a própria história da burocracia setorial, os atores políticos e sociais envolvidos, a existência de crises ou fatos marcantes, ações de lideranças fortes, os interesses daqueles que formataram as agências. Um estudo que busque a explicação da formatação e dos resultados de um órgão burocrático deve, necessariamente, partir de uma avaliação histórica que contextualize o setor e mapeie os atores relevantes.

Ainda que isso não fosse um objetivo declarado, o formato das agências reguladoras acabou por proporcionar maior accountability dos órgãos em relação à burocracia que atuava anteriormente nos setores, o que vai na mesma direção da conclusões apresentadas por Thatcher (2002) em relação aos reguladores europeus. Isso é uma inovação relevante no setor público. A disponibilidade de relatórios, a realização de consultas públicas abertas, acesso às atas com as decisões são novidades que poderiam ser incorporadas por outros órgãos da burocracia estatal e que, de certa forma, estavam previstas na

\footnotetext{
${ }^{3}$ A Câmara de Saúde Suplementar era parte do Conselho Nacional de Saúde Suplementar (Consu), cuja composição foi alterada ao longo do tempo. 
proposta do Plano Diretor da Reforma do Aparelho de Estado, pois ampliam a prestação de contas, a participação dos cidadãos, a explicitação de conflitos de interesses e a responsabilização. Esses pontos são a essência da accountability e da ampliação dos espaços democráticos do Estado moderno.

Ainda é necessário refinar e complementar as observações utilizadas neste estudo, porém os dados apontam para duas conclusões: o formato institucional, incluindo-se as regras, não garante resultados iguais se aplicados em contextos diferentes; contudo, o formato e as regras interferem no comportamento da burocracia e dos atores de cada setor, permitindo a ampliação da accountability e do espaço democrático. O quanto as regras importam ou o quanto se deve à influência da história de cada instituição é a pergunta essencial para entender melhor e aperfeiçoar o Estado brasileiro, questão para qual este estudo aponta algumas evidências, mas que novas pesquisas terão de aprofundar.

\section{Referências bibliográficas}

ABRANCHES, S. H. H. Reforma regulatória: conceitos, experiências e recomendações. Revista do Serviço Público, v. 50, n. 2, abr./jun. 1999.

BRASIL. Ministério da Administração e Reforma do Estado. Plano Diretor da Reforma do Aparelho do Estado. Brasília, 1995.

CARDOSO, F. H. Autoritarismo e democratização. Rio de Janeiro: Paz e Terra, 1975.

CLAD (CENTRO LATINOAMERICANO DE ADMINISTRACIÓN PARA EL DESARROLLO). La responsabilización en la nueva gestión pública latinoamericana. Buenos Aires: Eudeba, 2000.

COSTA, V. M. F. A dinâmica institucional da reforma do Estado: um balanço do período FHC. In: ABRUCIO, F. L.; LOUREIRO, M. R. (Orgs.). O Estado numa era de reformas: os anos FHC. Brasília: MP/Seges, 2002.

CUNILL GRAU, N. Responsabilización por controle social. In: CENTRO LATINOAMERICANO DE ADMINISTRACIÓN PARA EL DESARROLLO (CLAD). La responsabilización en la nueva gestión pública latinoamericana. Buenos Aires: Eudeba, 2000.

DAHL, R.; LINDBLOM, C. Política, economia e bem-estar social. Rio de Janeiro: Lidador, 1971.

GOUVÊA, G. Burocracia e elites burocráticas no Brasil. São Paulo: Paulicéia, 1994.

GRUBER, J. Controlling bureaucracies: dilemmas in democratic governance. Berkeley: University of California Press, 1987.

MAJONE, G. Do Estado positivo ao Estado regulador: causas e conseqüências de mudanças no modo de governança. Revista do Serviço Público, v. 50, n. 1, jan./mar. 1999.

MARTINS, H. Falcão. Reforma do Estado e coordenação governamental: as trajetórias das políticas de gestão pública na era FHC. In: ABRUCIO, F. L.; LOUREIRO, M. R. (Orgs.). O Estado numa era de reformas: os anos FHC. Brasília: MP/Seges, 2002. 
MEIER, K. J. Regulation. Politics, bureaucracy, and economics. New York: St. Martin's Press, 1985.

MELO, M. A. A política da ação regulatória: responsabilização, credibilidade e delegação. Revista Brasileira de Ciências Sociais, v. 16, n. 46, jun. 2001.

. As agências regulatórias: gênese, desenho institucional e governança. In: ABRUCIO, F. L.; LOUREIRO, M. R. (Orgs.). O Estado numa era de reformas: os anos FHC. Brasília: MP/Seges, 2002.

MUELLER, B.; PEREIRA, C. Credibility and the design of regulatory agencies in Brazil. Brazilian Journal of Political Economy, v. 22, n. 3, p. 87, July/Sept. 2002.

NUNES, E. A gramática política do Brasil. 2. ed. Rio de Janeiro: Jorge Zahar, 1997.

Democracia e regulação no Brasil: gênese e intalação da Aneel, Anatel e ANP. Rio de Janeiro: Universidade Candido Mendes, CNPQ, 2005. Relatório de pesquisa, v. 1.

OSLAK, O. Estado e sociedade: novas regras de jogo? In: DINES, A. et al. Sociedade e Estado: superando fronteiras. São Paulo: Edições Fundap, 1998.

PECI, A. Novo marco regulatório para o Brasil da pós-privatização: o papel das agências reguladoras em questão. Revista Brasileira de Administração, Rio de Janeiro, v. 33, n. 4, 1999.

PÓ, M. V. A accountability no modelo regulatório brasileiro: gênese e indefinições (os casos da Anatel e ANS). 2004. Dissertação (Mestrado) — Escola de Administração de Empresas de São Paulo, Fundação Getulio Vargas, São Paulo.

POLLITTI, C. Understanding public management reform. São Paulo, 2002. ms.

PRZEWORSKI, A. O Estado e o cidadão. In: BRESSER-PEREIRA, L. C. et al. Sociedade e Estado em transformação. Brasília: Unesp, 1999.

SANTANA, A. O processo de agencificação: pressupostos do modelo brasileiro e balanço da experiência. Brasília, 2002. Disponível em: <www.gestaopublica.gov.br>.

THATCHER, M. Regulation after delegation: independent regulatory agencies in Europe. Journal of European Public Policy, n. 9, p. 6, Dec. 2002.

WILSON, J. Q. Bureaucracy: what government agencies do and why they do it. New York: Basic Books, 1989.

\section{Web sites}

Anatel: <www.anatel.gov.br $>$.

Aneel: <www.aneel.gov.br>.

ANS: <www.ans.gov.br $>$.

ANTT: <www.antt.gov.br>.

Câmara dos Deputados: <www.camara.gov.br>

Presidência da República: <www.planalto.gov.br>.

Senado Federal: <www.senado.gov.br>.

Rap Rio de Janeiro 40(4):679-98, Jul./Ago. 2006 